\title{
Innovative Features Selection using Real Options Theory
}

\author{
Mahvish Khurum, Sebastian Barney \\ Blekinge Institute of Technology \\ S-372 25, Ronneby, Sweden \\ mahvish.khurum@bth.se,sebastian.barney@bth.se
}

\begin{abstract}
Innovation enables product differentiation and supports market growth. However, determining the value of an innovative feature is a difficult task due to the number of risks and uncertainties involved. This paper proposes the use of real options theory to support software product managers to decide whether to make an investment in an innovative feature or not. This approach creates a richer decision space, allowing for more informed decisionmaking, leading to greater return on potential.
\end{abstract}

\section{Introduction}

Requirements selection is a very important phase in the continuous development of a software product [14]. Decisions made at this stage have a great impact on the kind of features packaged in a product's release. In today's rapidly changing business environment, requirements engineering (RE) has transformed from a traditional bespoke approach towards a market-driven one. Today managers take a more proactive approach and operate strategically, taking early decisions by gathering requirements to improve a product's market value. Requirements today include innovative features whose potential and value is hard to estimate, in addition to the ones gathered from stakeholders.

Innovations play a major role for any product in the market by creating competitive advantage, opportunities for company to evolve market trends, and expand the client base. But for realizing these innovative features market uncertainty can become a major risk. A strategic and proactive approach in decision making becomes essential and this increases a product manager's responsibilities. He has to think and act by analyzing various possibilities and perspectives to balance product value, company vision and mission, targeting and creating a market, killing market competition, and enhancing a product's portfolio; but all in a specified time with available budget and resources [4].
This paper presents how the concept of option space [5] can be used for selecting and planning innovative features given the uncertainty involved and the time left, to take a decision.

The paper is structured as follows. Background to the current method used for determining the value of major investments and real options is presented in Section 2. Section 3 contains an example showing how real options can be used for making decisions about innovative features. Section 4 summarizes the paper.

\section{Background}

Today the most established method for valuing long-term investments is net present value (NPV) [6, 7]. This metric uses estimated cash flows (in and out), adjusted against the risk-free interest rate to determine if an investment will turn a profit. If NPV is positive the investment is expected to make a profit, while if it is negative it is expected to loose money, and a result of zero translates to breaking even.

There are a number of problems with NPV that make it unsuitable for determining the value of some investments under uncertainty [8]. Perhaps most problematic with regard to innovation as it assumes risk levels and returns are static, despite this rarely being the case when dealing with innovative features.

NPV also assumes two possible scenarios for a given investment opportunity - invest now in full or never invest [8]. It is important to recognize that many investments do not need to be made immediately companies should not only decide if an investment should be realized, but when it should be realized and to what extent. It is possible to reduce risk by gathering more information before investing the full amount of required funds through activities like prototyping, research, experiments and market surveys. Each of these activities provide a company with more information with which to make future investment decisions - allowing for more informed choices to be made, whether the company should proceed or cancel an ongoing investment. 
Recognizing the problems with NPV, a number of software economics researchers have proposed the application of real options theory to the software development domain as a possible alternative to NPV [7-12].

Real options theory is based on financial options. A financial option is an agreement between two parties. It gives one party the right, but not the obligation, to buy or sell an asset at, or before, a specified future date and at a set price from the other party. The major differences between real and financial options are that the real options are internal to one company and they concern "real" and not financial assets [8].

Options-thinking brings with it a sophisticated valuation method that addresses a number of problems with NPV [8] - the Black-Scholes pricing model. This model provides decision makers with richer information than NPV, as it takes into account:

- The uncertainty of expected cash flows,

- The present value of expected cash flows,

- The value lost over duration of option,

- The risk-free interest rate,

- The present value of fixed costs, and

- The time to expiry of the option.

The Black-Scholes model for pricing options includes all of the information required for the NPV calculation, but also metrics on volatility and the amount of time it is possible to delay making a decision. It is also possible to visualize option space in a two-dimensional graph, as shown in Figure 1 - with expected profitability on the $\mathrm{x}$-axis and the volatility on the y-axis [5].

It is possible to split the graph of option space into a number of regions [5]. When the volatility of an investment is low an investment decision can be made whether the value-to-cost ratio is greater than one (invest now, Region 1 in Figure 1) or less than one (do not invest, Region 6 in Figure 1). The value-to-cost ratio defines whether the option is expected to make a profit by dividing the expected cash inflow by the expected cash outflow, adjusting for the risk-free interest rate. The volatility of an investment will decrease over time as more becomes known about the investment.

Looking at in Figure 1, if the value-to-cost ratio is greater than one, it is expected that the investment will be profitable. However, increasing volatility means that there is a higher risk this will not be the case. Thus, we can divide these options into two cases - ones in which to maybe now invest (Region 2 in Figure 1), and one in which to probably later invest (Region 3 in Figure 1). Given that the volatility will decrease as the investment gets closer to the exercise date; it is possible to delay the investment decision to later.

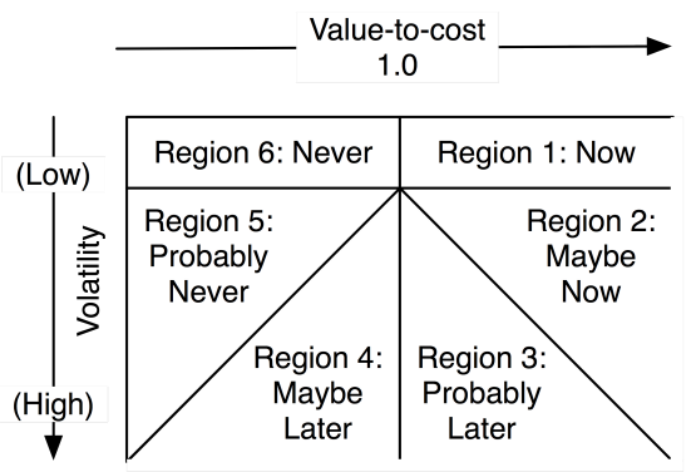

Figure 1 - Investments in real option space [5]

However, investments with a value-to-cost ratio that is less than one should not be instantly discarded. Just as higher volatility means some investments perceived as profitable may not be, it also means that some investments perceived as unprofitable may turn out profitable. The more profitable and volatile investments have the greatest chance of becoming profitable and can be considered for investment maybe later (Region 4 in Figure 1).

It is important to manage investment options, even prior to a decision on whether they should be exercised [5]. Over time options will naturally decrease in volatility and value, however, it is possible to nurture these investments to increase their profitability. Working to reduce costs, increase sales, or reduce fixed costs all help increase the profitability of an investment prior to deciding whether or not to make the investment.

While Racheva et al. [13] have discussed application of real options for requirements prioritization in the projects' context, the approach presented here particularly discusses long term investments in innovative features instead of agile requirements prioritization in projects.

\section{Real Options for Making Decisions about Innovative Features}

Using this understanding of real options, it is possible to define innovative features as a specific type of real options, and exploit the benefits and management opportunities that come with it. This section illustrates the use of real options in a product management scenario.

The definitions of factors used for calculating the value of real options for the innovative features (exemplified in the next section) are given in Table 1. 


\subsection{Example Scenario}

There is a leading telecommunication company that provides a wide range of products and solutions. Products are developed and sold as generic solutions offered to an open market, although customized versions of the products are also developed for key customers.

The research and development department has forecasted trends for the coming years as innovative features. The product management wants to decide which innovative features (or options) should be implemented (utilized) or discarded now, and which ones to delay introducing. The features marked as F1, F2....F6 are described as below [14].

F1 - Sensors everywhere: The mobile phone has a lot of information about the world around its user. If we take that information and combine it with the information from every other phone, it is possible to provide an snapshot of what is going on in the world right now and offer this to the user.

F2 - Smart alerts: The phone is aware of your situation and alerts its user when something needs his/her attention.

F3 - Tool for economic development: The phone can be more than just a convenience; it can be the user's livelihood. For example, in South Africa, sugar farmers can receive text messages advising them of how much to irrigate their crops

F4 - The future-proof device: Just as the Internet already has made it easy to provide users with access to content and services, opening up the phone can make it easy for developers to create and improve applications and content for the mobile market. The applications and services that a user cares about can then get automatically installed on your phone.

F5 - Safer software through trust and verification: The phone provides tools and information to empower its user to decide what to download, what to see, and what to share. Trust is the most important currency in the always connected world, and the phone can help a user stay in control of his/her information

F6 - Augmented reality: The phone uses its arsenal of sensors to understand its user's situation and provide him/her with information that might be useful.

Table 2 shows categorization of F1-F6 in the option space based on value-to-cost metrics, NPV and volatility metrics. Note that each of them involves assets of $\$ 5$ million. Two of them (F2, F3) require capital expenditures of $\$ 4$ and $\$ 3$ respectively; the other four require expenditures of more than the asset value. Consequently, F2 and F3 have positive NPVs of $\$ 1$ million and \$2 million respectively whereas each of the other four has negative NPV. Conventional capital budgeting offers only two prescriptions - invest or do not invest which when applied in this scenario means accept $\mathrm{F} 2$ and $\mathrm{F} 3$ and reject all the others.

Although their NPVs are very close, the six features (F1, F4, F5, and F6) have different time to expiration and volatility profiles, which gives different values for their value-to-cost and volatility metrics. This makes them fall into different regions of the option space.

Table 1 - Factors affecting the value of an option

\begin{tabular}{|l|l|}
\hline $\begin{array}{l}\text { Underlying asset } \\
\text { value (S) }\end{array}$ & $\begin{array}{l}\text { Current value of implementing a } \\
\text { feature }\end{array}$ \\
\hline $\begin{array}{l}\text { Exercise price } \\
(\mathrm{X})\end{array}$ & $\begin{array}{l}\text { Cost of implementing a feature } \\
\text { including the cost of legacy migration }\end{array}$ \\
\hline Volatility $(\partial)$ & Uncertainty of customers demand \\
\hline $\begin{array}{l}\text { Time to } \\
\text { expiration (T) }\end{array}$ & $\begin{array}{l}\text { Market window for a feature before it } \\
\text { is no longer demanded }\end{array}$ \\
\hline $\begin{array}{l}\text { Net Present } \\
\text { Value (NPV) }\end{array}$ & $\begin{array}{l}\text { The underlying asset value (S) minus } \\
\text { the exercise price }(\mathrm{X}) \text {. }\end{array}$ \\
\hline $\begin{array}{l}\text { Value to cost } \\
\text { metric }\left(\mathrm{NPV} \mathrm{q}_{\mathrm{q}}\right)\end{array}$ & $\begin{array}{l}\text { The value of implementing a feature } \\
\text { divided by the present value of the } \\
\text { expenditure required. }\end{array}$ \\
\hline $\begin{array}{l}\text { Volatility metric } \\
\left(\partial(\mathrm{T})^{1 / 2}\right)\end{array}$ & $\begin{array}{l}\text { Measure of level of changes before an } \\
\text { investment decision must be made. }\end{array}$ \\
\hline
\end{tabular}

F1 is a never feature in Region 6, F2 falls into Region 1. Since for both of them time has run out making volatility metric 0 . From Table 2 it is possible to see that F3 seems to be promising as its NPV is positive and its $\mathrm{NPV}_{\mathrm{q}}$ is greater than one. This makes it fall into Region 3 meaning that it can be considered for early implementation (exercised). However, unless there is some predictable loss in future value (either a rise in development cost or decrease in value), then early implementation is unnecessary and suboptimal. F4's $\mathrm{NPV}_{\mathrm{q}}$ is greater than 0 , but its NPV is less than zero. As a result it falls into Region 3 and is very valuable as an option, despite its negative NPV. This is due to the fact that it will not expire for four years and has quite a high volatility. Calculations in Table 2 show that F5 falls into Region 4 with two years to go and the moderate $\partial=0.3$ per year, it just might make it. F6 seems to be less promising as the decision has to be made in less than a year, the volatility is low, and thus there is not much probability that F6 will become profitable before the time runs out.

As a real options based frameworks can account for flexibility and uncertainty, it produces a different estimation of the features to the conventional NPV methods. It can be evidently seen that NPV method gives a value of $\$ 3$ million, while option-pricing gives a value of $\$ 4.61$ million, which is almost double. By placing the innovative features in different regions of 
Table 2 - Vital Statistics for Feature F1-F6

\begin{tabular}{|c|c|c|c|c|c|c|c|}
\hline Variables & & F1 & F2 & F3 & F4 & F5 & F6 \\
\hline $\mathrm{S}$ & Underlying asset value (\$ million) & 5 & 5 & 5 & 5 & 5 & 5 \\
\hline $\mathrm{X}$ & Exercise price (\$ million) & 7 & 4 & 3 & 7 & 6 & 6 \\
\hline $\mathrm{T}$ & Time to expiration & 0 & 0 & 2 & 4 & 2 & 0.5 \\
\hline$\partial$ & Standard deviation (per year) & .3 & .3 & .3 & .8 & .3 & .4 \\
\hline $\mathrm{R}_{\mathrm{f}}$ & Risk-free rate of return & .05 & .05 & .05 & .05 & .05 & .05 \\
\hline $\mathrm{NPV}$ & Value to cost metric & .78 & 1.25 & 1.83 & 1.86 & .919 & .854 \\
\hline$\partial(\mathrm{T})^{1 / 2}$ & Volatility metric & 0 & 0 & .424 & 1.6 & .424 & .282 \\
\hline $\mathrm{C}$ & Call value(\$ million) & 0 & 1.00 & 2.023 & 1.02 & .109 & .458 \\
\hline $\mathrm{S}-\mathrm{X}$ & Conventional NPV (\$ millions) & -2 & 1 & 2 & -2 & -1 & -1 \\
\hline & Region in option space & 6 & 1 & 2 & 3 & 4 & 5 \\
\hline & Exercise decision & Never & Now & $\begin{array}{c}\text { Maybe } \\
\text { Now }\end{array}$ & $\begin{array}{c}\text { Probably } \\
\text { later }\end{array}$ & $\begin{array}{c}\text { Maybe } \\
\text { later }\end{array}$ & $\begin{array}{c}\text { Probably } \\
\text { never }\end{array}$ \\
\hline
\end{tabular}

which features to select/reject for implementation now and wait for certain features as their prospects can differ with time.

\section{Summary}

The very nature of innovation makes its very uncertain which innovative features to implement. While planning for innovative features, the use of real options provides the following benefits:

1. It provides a valuation method that can be used to analyze different future possibilities and make decisions other than now or never

2. With the use of a volatility metric, uncertainty is explicitly taken into account, something often missing in current decision making

3. These valuations can be repeated when new features are proposed and/or when there are changes in market and technology trends that can affect the volatility metric and $\mathrm{NPV}_{\mathrm{q}}$ metric to position/reposition features in the options space. For promising features in Regions 3 and 4 managers can proactively try to increase their value, for example by decreasing costs, saving taxes and/or through marketing campaigns.

4. The use of real options gives a homogenous decision support material that can be understood and used by all stakeholders from revenue management to product management to developers.

The concept of real options is not perfect, and displays some of the shortcomings of the other tools (for example financial options). However, the use of real options shown through an example in this paper seems usable and useful. Future work involves piloting the idea and refining it for the specific domain of software product development.

\section{References}

[1] T. Gorschek and A. M. Davis, "Requirements engineering: In search of the dependent variables," Information and Software Technology, vol. 50, pp. 67-75, 2008.

[2] T. Gorschek and C. Wohlin, "Requirements Abstraction Model," Requirements Engineering journal, vol. 11, pp. 79101, 2006.

[3] I. v. d. Weerd, S. Brinkkemper, R. Nieuwenhuis, J. Versendaal, and L. Bijlsma, "Towards a Reference Framework for Software Product Management," in Proceedings of the 14th IEEE International Requirements Engineering Conference: IEEE Computer Society, 2006.

[4] A. S. Dver, Software Product Management Essentials. Tampa, Florida: Anclote Press, 2003.

[5] T. A. Luehrman "Strategy as a Portfolio of Real Options," Harvard Business Review, pp. 89-99, September-October 1998 1998.

[6] T. Copeland and V. Antikarov Real options - A practitioner's guide: Texere, 2001.

[7] H. Erdogmus "Comparative evaluation of software development strategies based on net present value," in International Conference on Software Engineering Workshop on EconomicsDriven Software Engineering, 1999.

[8] A. K. Dixit and R. S. Pindyck, Investment under Uncertainty Princeton University Press, 1993.

[9] B. Boehm, "Value-based software engineering," Software Engineering Notes, vol. 28, pp. 1-12, 2003.

[10]J. M. Favaro, K. R. Favaro, and P. F. Favaro "Value based software reuse investment," Annals of Software Engineering, 1998.

[11]B. Boehm and K. Sullivan "Software economics: A roadmap," in International Conference on Software Engineering (ICSE) Limerick, Ireland, 2000.

[12]K. Sullivan, P. Chalasani, and S. Jha, "Software design decisions as real options," IEEE Transactions on Software Engineering, 1997.

[13]Z. Racheva, M. Daneva, and L. Buglione, "Complementing measurements and real options concepts to support interiteration decision-making in agile projects," Piscataway, NJ, USA, 2008, pp. 457-64.

[14] A. Rubin, "The future of mobile, http://googleblog.blogspot.com/search/label/mobile," 2008. 